\title{
HUBUNGAN TINGKAT PENGETAHUAN IBU TENTANG KLIMAKTERIUM DENGAN KESIAPAN IBU MENGHADAPI MASA KLIMAKTERIUM DI PADUKUHAN PUNDUNG TIRTOMARTANI KALASAN
}

\author{
Oleh; \\ Florentina Kusyanti ${ }^{1)}$ \\ 1) Dosen Prodi D-3 Kebidanan UNRIYO,Email; florenkusyanti68@gmail.com
}

\begin{abstract}
ABSTRAK
Latar Belakang: Masa klimakterium merupakan masa peralihan dari masa reproduksi ke masa senium, dimana seorang wanita akan mengalami berbagai perubahan fisik maupun psikis. Dalam perubahan itu, seorang wanita membutuhkan kesiapan untuk menerima suatu keadaan yang dialaminya. Kesiapan akan dipengaruhi oleh pengetahuan seorang wanita tersebut. Berdasarkan studi pendahuluan di Padukuhan Pundung Tirtomartani Kalasan, dari 10 orang ibu terdapat $3 \mathrm{ibu}(30 \%)$ memiliki pengetahuan yang baik dan $7 \mathrm{ibu}$ (70\%) memiliki pengetahuan yang kurang mengenai klimakterium. Diketahuinya tingkat pengetahuan ibu tentang klimakterium di Padukuhan Pundung Tirtomartani Kalasan dapat mempengaruhi kesiapan ibu dalam menghadapi masa klimakterium.
\end{abstract}

Metode: Penelitian dilaksanakan di Padukuhan Pundung Tirtomartani Kalasan. Menggunakan metode deskriptif korelasional dan desain penelitiannya adalah cross-sectional. Subyek penelitian adalah ibu yang berusia 40-49 tahun dan masih mengalami haid. Penelitian ini menggunakan teknik sampel total sampling dan sampel di penelitian ini adalah 48 responden. Alat pengumpulan data menggunakan kuesioner.

Hasil: Ibu di Padukuhan Pundung Tirtomartani Kalasan mayoritas $(58,3 \%)$ berada pada umur 40-45 tahun, mayoritas $(33,3 \%)$ berpendidikan SMP, mayoritas $(83,3 \%)$ bekerja sebagai ibu rumah tangga, dan mayoritas $(87,5 \%)$ mendapatkan informasi dari tenaga kesehatan. Mayoritas $(60,4 \%)$ pengetahuan ibu di Padukuhan Pundung Tirtomartani Kalasan berada dalam kategori baik, sedangkan $(39,6 \%)$ berada dalam kategori cukup. Mayoritas $(66,7 \%) \mathrm{ibu}$ di Padukuhan Pundung Tirtomartani Kalasan pada tahun 2014 mempunyai kesiapan dalam kategori siap, sedangkan $(33,3 \%)$ ibu mempunyai kesiapan dalam kategori tidak siap. Hasil survey deskriptif yang didapat chi-square hitung adalah 17,423 dan p-value adalah 0,000. Nilai $C$ (koefisien kontingensi) $=0,516$ yang berarti ada hubungan antara tingkat pengetahuan ibu tentang klimakterium dengan kesiapan ibu menghadapi masa klimakterium di Padukuhan Pundung Tirtomartani Kalasan dan memiliki keeratan yang sedang.

Kesimpulan: Ada hubungan tingkat pengetahuan ibu tentang klimakterium dengan kesiapan ibu menghadapi masa klimakterium di Padukuhan Pundung Tirtomartani, Kalasan.

Kata Kunci: Tingkat Pengetahuan, Kesiapan, Klimakterium. 


\title{
THE RELATIONSHIP OF MOTHER KNOWLEDGE LEVEL ABOUT \\ CLIMACTERIUM WITH THE READINESS OF MOTHER FACING THE CLIMACTERIUM TIME IN PADUKUHAN PUNDUNG TIRTOMARTANI KALASAN
}

\author{
By; \\ Florentina Kusyanti ${ }^{1)}$ \\ 1) Lecturer of D-3 Midwifery UNRIYO, Email; florenkusyanti68@gmail.com
}

\begin{abstract}
Background: The climacterium period is a transition from reproductive to senium, where a woman will experience various physical and psychological changes. In that change, a woman needs readiness to accept a situation she experiences. Readiness will be influenced by a woman's knowledge. Based on a preliminary study in Pundung Tirtomartani Kalasan Padukuhan, out of 10 mothers, 3 mothers (30\%) had good knowledge and 7 mothers (70\%) had less knowledge about climacterium. This purpose of this study is knowing the level of maternal knowledge about climacterium in Pundung Tirtomartani Kalukuhan Padukuhan can affect the readiness of mothers in facing the climacteric period.

Methods: The study was conducted in Padunduhan Pundung Tirtomartani Kalasan. Using a correlational descriptive method and the research design is cross-sectional. Research subjects were mothers aged 40-49 years and still having menstruation. This study uses a total sampling technique and the sample in this study is 48 respondents. Data collection tool uses a questionnaire.

Result: The majority of mothers in Pundung Tirtomartani Kalasan (58.3\%) were at the age of 40-45 years, the majority (33.3\%) had a junior high school education, the majority (83.3\%) worked as housewives, and the majority (87 5\% get information from health workers. The majority (60.4\%) of mothers' knowledge in Pundung Tirtomartani Kalasan Padukuhan are in the good category, while (39.6\%) are in the sufficient category. The majority (66.7\%) of mothers in Pundung Tirtomartani Kalasan Padukuhan in 2014 had readiness in the ready category, while (33.3\%) mothers had readiness in the unprepared category. The descriptive survey results obtained by chi-square calculation were 17,423 and p-value was 0,000. C value (contingency coefficient) $=0.516$ which means that there is a relationship between the level of maternal knowledge about climacterium and the readiness of mothers to face the climacteric period in Pundung Tirtomartani Kalasan Padukuhan and have moderate closeness.

Conclusion: There is a correlation between the level of maternal knowledge about climacterium and the readiness of mothers to face the climacteric period in Padunduhan Pundung Tirtomartani, Kalasan.
\end{abstract}

Keywords: Level of Knowledge, Readiness, Climacterium 


\section{PENDAHULUAN}

Menurut WHO, di kawasan Asia Tenggara populasi lansia sebesar $8 \%$ atau sekitar 142 juta jiwa. Sedangkan di Indonesia sendiri pada tahun 2020 diperkirakan jumlahnya sekitar 80.000.000 (DepKes RI. 2013)

Berdasarkan data dari Badan Pusat Statistik (BPS) dengan proyeksi penduduk tahun 2010 bahwa 5.330.400 jiwa wanita Indonesia memasuki masa penuaan. Masa penuaan yang dimaksud adalah masa dimana seorang wanita mulai mengalami perubahan siklus haid atau masa premenopause (Proverawati, 2010)

Pada fase klimakterium ini seorang wanita akan mengalami kekacauan menstruasi, akan terjadi perubahan psikologis dan perubahan fisik yang berlangsung 4-5 tahun. Fase ini terjadi pada usia 40 tahun dan dimulainya fase klimakterium (Mulyani, 2013)

Selain itukebutuhan utam dan kuat mendorong individu dalam hubungan keluarga seperti kebutuhan seksualitas relatif kurang dapat terpenuhi dengan baik sehingga semakin memunculkan ketakutan dan kecemasan, maka dalam hal seperti itu seorang wanita harus mempunyai kesiapan dalam menghadapi masa klimakterium ini (Proverawati, 2010)

Berdasarkan studi pendahuluan yang dilaksanakan pada tanggal 5 Februari 2014 di Padukuhan Pundung Tirtomartani
Kalasan, diperoleh data bahwa terdapat 58 orang sedang menghadapi masa klimakterium (usia 40 - 49 tahun).

$$
\text { Hasil wawancara dengan }
$$

mengajukan 5 pertanyaan terhadap 10 orang diperoleh data sebanyak 3 orang (30\%) bisa menjawab 4 dari pertanyaan yang diajukan, dimana pertanyaan yang bisa dijawab mengenai masa klimakterium atau masa premenopause yaitu dari pengertian masa klimakterium, gejala yang timbul, faktor-faktor yang mempengaruhi dan persiapan apa saja yang harus disiapkan saat masa klimakterium. Sedangkan 7 orang (70\%) hanya bisa menjawab 3 pertanyaan diantaranya mengenai pengertian klimakterium, gejala yang timbul, dan faktor-faktor yang mempengaruhi.

\section{RUMUSAN MASALAH}

Berdasarkan latar belakang maka rumusan masalah dari penelitian ini adalah apakah ada hubungan tingkat pengetahuan ibu tentang klimakterium dengan kesiapan ibu menghadapi masa klimakterium di Padukuhan Pundung Tirtomartani, Kalasan?

\section{TUJUAN PENELITIAN}

1. Mengetahui karakteristik responden (seperti umur, pendidikan, pekerjaan dan sumber informasi). 
2. Mengetahui tingkat pengetahuan ibu tentang klimakterium di Padukuhan Pundung Tirtomartani, Kalasan.

3. Mengetahui kesiapan ibu menghadapi masa klimakterium di Padukuhan Pundung Tirtomartani, Kalasan.

4. Mengetahui keeratan hubungan tingkat pengetahuan ibu tentang klimakterium dengan kesiapan ibu menghadapi masa klimakterium di Padukuhan Pundung Tirtomartani, Kalasan.

\section{METODOLOGI}

1. Jenis Penelitian

Penelitian ini penelitian deskriptif korelasi karena penelitian dilakukan untuk mengetahuai hubungan tingkat pengetahuan dengan kesiapan ibu menghadapi klimaktorium di Padukuhan Pundung Tirtomartani Kalasan, sedangkan pendekatannya dengan cross sectional dimana variabel tingkat pengetahuan dan kesiapan menghadapi klimaktorium diambil secara bersamaan atau dalam waktu yang sama (Arikunto, 2010)

2. Populasi

Populasi pada penelitian ini adalah semua ibu yang berumur 40-49 tahun yang masih mengalami haid sejumlah 48 orang dipadukuhan Padukuhan Pundung Tirtomartani Kalasan.
3. Tehnik sampel

Teknik sampel yang dipakai pada penelitian ini adalah dengan menggunakan total sampling, seluruh sampel berjumlah 48 orang.

\section{HASIL}

1. Karakteristik Responden

Tabel 1 : Distribusi Frekuensi Karakteristik Responden

\begin{tabular}{|c|c|c|}
\hline Karakteristik & $\mathbf{n}$ & $\%$ \\
\hline \multicolumn{3}{|l|}{ Umur } \\
\hline 40 - 45 tahun & 28 & 58,3 \\
\hline $46-49$ tahun & 20 & 41,7 \\
\hline Total & 48 & 100 \\
\hline \multicolumn{3}{|l|}{ Pendidikan } \\
\hline SD & 13 & 27,1 \\
\hline SMP & 16 & 33,3 \\
\hline SMA/SMU & 15 & 31,3 \\
\hline Perguruan Tinggi & 4 & 8,3 \\
\hline Total & 48 & 100 \\
\hline \multicolumn{3}{|l|}{ Pekerjaan } \\
\hline Ibu Rumah Tangga & 40 & 83,3 \\
\hline Buruh Tani & 5 & 10,4 \\
\hline Pegawai Negeri & 2 & 4,2 \\
\hline Swasta & 1 & 2,1 \\
\hline Total & 48 & 100 \\
\hline \multicolumn{3}{|l|}{ Sumber Informasi } \\
\hline Tenaga Kesehatan & 42 & 87,5 \\
\hline Teman & 5 & 10,4 \\
\hline Media Elektronik & 1 & 2,1 \\
\hline Total & 48 & 100 \\
\hline
\end{tabular}

Data primer tahun 2014 
2. Analisis Univariat

Tabel 2 : Distribusi Frekuensi Tingkat Pengetahuan Ibu

\begin{tabular}{|c|c|c|}
\hline Tingkat pengetahuan & $\mathbf{f}$ & $\%$ \\
\hline Cukup & 19 & 39,6 \\
\hline Baik & 29 & 60,4 \\
\hline Total & 48 & 100 \\
\hline
\end{tabular}

Tabel 3 : Distribusi Frekuensi Kesiapan Ibu Menghadapi Masa Klimakterium

\begin{tabular}{lcc}
\multicolumn{1}{r}{ Kesiapan ibu } & n & \% \\
\hline Siap & 32 & 66,7 \\
Tidak Siap & 16 & 33,3 \\
\hline \multicolumn{1}{c}{ Total } & $\mathbf{4 8}$ & $\mathbf{1 0 0}$
\end{tabular}

Data primer 2014

Data primer 2014

3. Analisa Bivariate

Tabel 4 : Hubungan Tingkat Pengetahuan Ibu tentang Klimakterium dengan Kesiapan Ibu Menghadapi Masa Klimakterium

Kesiapan ibu

\begin{tabular}{|c|c|c|c|c|c|c|c|}
\hline \multirow{3}{*}{ Tingkat pengetahuan ibu } & & & & & & \multirow{3}{*}{$\begin{array}{c}\text { p } \\
\text { value }\end{array}$} & \multirow{3}{*}{$\mathbf{C C}$} \\
\hline & \multicolumn{2}{|c|}{ Siap } & \multicolumn{3}{|c|}{ Tidak siap } & & \\
\hline & $\mathbf{n}$ & $\%$ & $\mathbf{n}$ & $\%$ & tot & & \\
\hline Baik & 3 & 6,3 & 26 & 54,2 & 60,5 & 0,000 & 0,516 \\
\hline Cukup & 13 & 27,1 & 6 & 12,5 & 39,5 & & \\
\hline Total & 16 & 33,3 & 32 & 66,7 & 100 & & \\
\hline
\end{tabular}

Berdasarkan tabel 4 menunjukkan bahwa hubungan tingkat pengetahuan ibu tentang klimakterium dengan kesiapan ibu dalam menghadapi masa klimakterium pada tahun 2014, diperoleh hasil bahwa responden yang mempunyai pengetahuan baik tetapi ibu tidak siap menhadapi klimaktorium sebesar 54,2 \%,dan ibu yang mempunyai pengetahuan dalam kategori cukup namun memiliki kesiapan dalam menghadapi klimaktorium sebesar 27,1\%.

Berdasarkan hasil uji hipotesis menggunakan chi-square diperoleh nilai pvalue $=0,000$ dimana $p$-value $<\alpha$
$(0,000<0,05)$ secara statistik dapat diartikan bahwa $\mathrm{H} 0$ ditolak dan $\mathrm{H} 1$ diterima.

Hal tersebut dapat diartikan bahwa terdapat hasil yang signifikan antara tingkat pengetahuan ibu dengan kesiapan ibu dalam menghadapi masa klimakterium. Uji hubungan dengan koefisien kontingensi nilai $\mathrm{C}=0,516$, hal ini berarti ada hubungan signifikan antara tingkat pengetahuan $\mathrm{ibu}$ tentang klimakterium dengan kesiapan ibu menghadapi masa klimakterium, sedangkan keeratan hubungan pada hubungan antara tingkat 
pengetahuan dengan kesiapan ibu dalam menghadapi klimaktorium dengan kekuatan sedang.

Dapat diartikan masih ada faktor lain yang mempengaruhi kesiapan ibu dalam menghadapi klimaktorium.sedang. Dapat diartikan bahwa ada faktor lain yang mempengaruhi kesiapan ibu dalam menghadapi masa klimakterium

(Notoatmodjo, 2010)

\section{PEMBAHASAN}

1. Karakteristik Ibu di Padukuhan Pundung Tirtomartani Kalasan

Hasil penelitian ini dalam karangteristik umur bahwa mayoritas ibu berumur antara usia 40 - 45 tahun sebesar 58,3\%. Hasil ini menunjukkan bahwa ibu kelompok PKK yang ada di Padukuhan Pundung Tirtomartani Kalasan berada dalam masa usia awal klimakterium, yang dimana pada masa ini seorang ibu akan mengalami penurunan hormon estrogen dan kenaikan hormon gonadotropin. Pada permulaan klimakterium kesuburan akan menurun (Mulyani, 2010). Seiring dengan bertambahnya umur seseorang maka ingatnya akan semakin menurun, sehingga seseorang itu akan mudah lupa akan informasi yang pernah didapatkannya dan mudah perasa dan mudah tersinggung. Usia mempengaruhi daya terima seseorang terhadap suatu informasi dimana informasi merupakan sarana untuk meningkatkan pengetahuan seseorang. (Notoatmodjo. 2007)

Pendidikan merupakan suatu proses penyampaian bahan atau materi kepada seseorang gunanya untuk mencapai perubahan tingkah laku atau tujuan (Notoatmodjo. 2007). Pada penelitian ini pendidikan paling bnayak adalah berpendidikan SMP sebesar $(33,3 \%)$. Pendidikan merupakan salah satu faktor yang dapat membantu seseorang menentukan pengetahuan, dan persepsi terhadap pentingnya meningkatkan sesuatu Ini, karena pendidikan akan mempengaruhi kehidupan seseorang, semakin tinggi pendidikan seseorang maka semakin luas pandangannya atau wawasannya, sehingga akan lebih mudah menerima idea atau tata cara kehidupan baru.

Pekerjaan merupakan suatu kegiatan yang dilakukan seseorang untuk menunjang/memenuhi kebutuhan hidup dirinya sendiri maupun orang lain. Dalam penelitian ini untuk pekerjaan, di Padukuhan Pundung Tirtomartani Kalasan mayoritas ibu kelompok PKK memiliki pekerjaan sebagai ibu rumah tangga sebesar $(83,3 \%)$. Pekerjaan bukanlah sumber kesenangan tetapi lebih banyak merupakan untuk mencari nafkah yang 
membosankan, berulang dan banyak tantangan (Wawan. 2011). Jika seseorang itu telah bekerja dan mempunyai penghasilan tetap maka status ekonominya akan tercukupi dan kehidupannya akan lebih baiknya juga.

Faktor ekonomi dalam keluarga sangat mempengaruhi tingkat pengetahuan pada responden, karena semakin tinggi atau semakin baik status ekonomi maka ketersediaan fasilitas atau sarana akan lebih memungkinkan untuk mendapatkan informasi yang dapat menunjang dalam meningkatkan pengetahuannya (Notoatmodjo, 2007)

Ibu di Padukuhan Pundung Tirtomartani Kalasan mayoritas mendapatkan informasi tentang klimaktorium yang berasal dari tenaga kesehatan sebesar $(87,5 \%)$ Semakin banyak sumber informasi yang dimiliki maka tingkat pengetahuan yang dimiliki akan semakin tinggi (Notoatmodjo, 2007)

2. Tingkat Pengetahuan Ibu tentang Klimakterium

Hasil penelitian yang telah dilakukan di Padukuhan Pundung Tirtomartani Kalasan, bahwa mayoritas memiliki pengetahuan yang baik mengenai klimaktorium sebesar $(60,4 \%)$ Hasil ini menunjukkan bahwa ibu kelompok PKK sangat aktif dalam mencari informasi8 (Ariani. 2013)

Dilihat dari pendidikannya, ibu PKK di Padukuhan Pundung Tirtomartani Kalasan paling banyak pendidikan terakhir adalah SMP sebesar $(33,3 \%)$ pendidikan terakhirnya SMP adalah ini menunjukkan bahwa ibu PKK sudah memenuhi kewajiban belajar yang telah ditentukan oleh pemerintah, semakin tinggi pendidikan maka semakin tinggi pula pengetahuannya. Pendidikan merupakan proses secara umum pengetahuan, ide, opini-opini, dari satu pihak ke pihak lain yang menyebabkan seseorang memiliki pengetahuan yang luas sehingga akan terjadi perubahan pada diri seseorang baik perilaku dalam berpikir, sikap, mental, maupun nilai-nilai dalam kehidupan (Notoatmodjo, 2010)

Hasil penelitian tentang pekerjaan, mayoritas adalah ibu tidak bekerja atau bekerja sebagai ibu rumah tangga sebesar $(83,3 \%)$ Sehingga ibu memiliki banyak waktu untuk mencari informasi baik dari teman, tetangga,media massa, media elektronik Ibu ini sangat aktif dalam mengikuti perkumpulan PKK dan mayoritas mendapatkan informasi dari tenaga kesehatan sebesar (87,5\%). Kelompok ibu PKK ini sering mendapat penyuluhan 
mengenai kesehatan, sehingga dengan penyuluhan tersebut dapat menambah pengetahuan ibu tentang masa klimakterium. Hubungan antara tingkat pengetahuan ibu tentang klimakterium dengan kesiapan menghadapi menopause (Dewanti, 2010). pengetahuan yang baik akan menyebabkan ibu lebih siap untuk menghadapi masa menopause.

3. Kesiapan Ibu Menghadapi Masa Klimakterium

Hasil penelitian ini menunjukkan bahwa mayoritas kesiapan ibu dalam menhadapi klimaktorium sebesar $(66,7 \%)$, ini dapat dilihat dari umur ibu yang mayoritas berumur 40-45 tahun sebesar $\quad(58,3 \%)$. Umur sangat berhubungan dengan kesiapan dan kematangan seseorang dalam berpikir dan dalam menerima informasi.

4. Hubungan Tingkat Pengetahuan Ibu tentang Klimakterium dengan Kesiapan Ibu Menghadapi Masa Klimakterium

Hasil penelitian ini menunjukkan semakin baik tingkat pengetahuan ibu maka semakin lebih siap dalam menghadapi masa klimakterium. Ibu yang memiliki karakteristik dalam umur 40 - 45 tahun memiliki kemampuan untuk lebih siap dalam menghadapi masa klimakterium dibandingkan yang mempunyai umur lebih muda atau lebih tua.dikarenakan umur seperti itu akan lebih memperhatikan keadaan dirinya, dari perubahan yang terjadi.

Pekerjaannya sebagai ibu rumah tangga memiliki banyak waktu dalam mencari informasi tentang klimakterium sehingga dapat meningkatkan pengetahuan mengenai masa klimakterium. Dengan pengetahuan yang lebih baik maka dapat mendukung dalam menghadapi masa klimakterium.

Berdasarkan hasil penelitian ini diperoleh nilai $\mathrm{p}$-value $=0,000<\alpha=$ 0,05 yang berarti ada hubungan antara tingkat pengetahuan ibu tentang klimakterium dengan kesiapan ibu menghadapi masa klimakterium, bahwa sebagian besar pengetahuan ibu di Padukuhan Pundung Tirtomartani Kalasan sudah baik.

5. Keeratan Hubungan Tingkat Pengetahuan Ibu tentang Klimakterium dengan Kesiapan Ibu Menghadapi Masa Klimakterium

Kekuatan hubungan menggunakan uji statistic koefisien kontingensi yang diperoleh hasil nilai yang diperoleh adalah sebesar 0,516 ini menunjukkan kuat hubungan antara tingkat 
pengetahuan dengan kesiapan ibu menghadapi masa klimakterium yang artinya hubungan tingkat pengetahuan ibu tentang klimakterium dengan kesiapan ibu menghadapi masa klimakterium dengan tingkat keeratan hubungan dalam kategori sedang.

Hal ini dapat menunjukan bahwa ada faktor lain yang mempengaruhi hubungan antara tingkat pengetahuan dengan kesiapan ibu menhadapi menopouse.

\section{DAFTAR PUSTAKA}

Arikunto, S. 2010. Prosedur Penelitian Suatu Pendekatan Praktek. Edisi Revisi. Jakarta: Rineka Cipta.

Ariani, Tutu. 2013. Sistem Neurobehaviour. Jakarta: Salemba Medika.

DepKes RI. 2013. Sensus Populasi Lansia di Indonesia. Jakarta: Departemen Kesehatan
Dewanti. 2010. Hubungan antara Tingkat Pengetahuan tentang Klimakterium dengan

Kesiapan Menghadapi Menopause di Dusun Tegal Senggotan, Tirtonirmolo, Kasihan, Bantul. KTI. Politeknik Kesehatan Yogyakarta.

Mulyani, Nina S. 2013. Manopause Akhir Siklus Menstruasi pada Wanita di Usia Pertengahan. Yogyakarta : Nuha Medika

Notoatmodjo. 2010. Promosi Kesehatan. Jakarta : Rineka Cipta.

Notoatmodjo. 2007. Metodologi Pendidikan Kesehatan. Jakarta : Rineka Cipta.

Proverawati, Atikah. 2010. Menopause dan Sindrome Premenopause. Yogyakarta : Nuha Medika.

Wawan, Dewi. 2011. Teori \& Pengukuran Pengetahuan, Sikap, dan Perilaku Manusia. Yogyakarta : Nuha Medika 